\title{
ANALYSIS OF MICROSTRIP PATCHES ANTENNAS ARRAY BY USING A NEW BOND GRAPH TECHNOLOGY
}

\author{
${ }^{1}$ Riadh Mehouachi, ${ }^{1,2}$ Taghouti Hichem and ${ }^{1,2}$ Abdelkader Mami \\ ${ }^{1}$ Department of Electrical Engineering, \\ Laboratory of Analysis and Command of the Systems, \\ ENIT-BP 37, 1002 Tunis Le BELVEDERE, Tunisia \\ ${ }^{2}$ Department of Physics, Faculty of Sciences of Tunis, \\ Electronic Laboratory, 2092 El Manar Tunisia
}

Received 2014-03-19; Revised 2014-04-10; Accepted 2014-06-30

\begin{abstract}
This study is the only one that combines the microstrip patch antennas representing the microwave domain and the bond graph technique representing the automatic domain. In this study, we propose a new methodology to analyses the microstrip patch antennas arrays: It is the bond graph technique and the wave scattering formalism. This method helps us to achieve our purpose which is to improve the analysis and comprehension of patch antenna arrays as the results found show.
\end{abstract}

Keywords: Scattering Matrix, Reduced Bond Graph, Patch Antenna Array, Reflection Coefficients, Ads Software

\section{INTRODUCTION}

Recently, microstrip patch antennas arrays have become a research topic among researches for the development of a new wireless communication technology. The highest gain of this type of antennas could be achieved by using a limited number of patch characterized by low profile, low volume, light weight and low fabrication cost. Moreover, this antenna has a planar configuration which can be mounted easily on all surfaces Ambresh et al. (2010). In this study, we propose the bond graph approach because this latter seems a very powerful technique to model and analyses microwave systems Paynter (1992) It also permits us to show up the arrays thanks to the causality assignment. At the beginning of this article, we will determine the simple and the precise electric model from the geometric measurements of one patch antenna Mehouachi et al. (2012a; 2012b). Then, we will move to the construction of the bond graph of this model. After that, we will transform this last model to the reduced bond graph model to determine the scattering matrix that allows us to find the reflection and cause/effect relations in different parts of patch antenna

transmission coefficients. Every time, we add another patch without forgetting to solve the problem of adaptation. We have to repeat the same gait for each patch added and to decompose each model into several submodel to simplify the modeling. Finally, we will repeat simulation with the conventional method which is simulation using ADS. By the end, we will compare the results found of the two methods.

\section{GEOMETRIC STRUCTURS PROPOSED OF PATCH ANTENNA ARRAY}

We propose a linear antenna array consisting of four patches. First, we start with a single patch and we add successively another element after the simulation to obtain the best gain. The antenna is characterized by a substrate material with a thickness $\mathrm{H}=3.2 \mathrm{~mm}$, a relative permittivity $\varepsilon_{\mathrm{r}}=2.6$, loss $(\operatorname{tang} \delta)=0.002$ and it has an edge $\mathrm{L}=\mathrm{W} 2=36 \mathrm{~mm}$ Mehouachi et al. (2012a) W3 = 10 $\mathrm{mm}$. Figure 1 shows a linear array consisting of $n$ antennas deposited along the axis Ox. Corresponding Author: Riadh Mehouachi, Department of Electrical Engineering, Laboratory of Analysis and Command of the Systems, ENIT-BP 37, 1002 Tunis Le BELVEDERE, Tunisia 


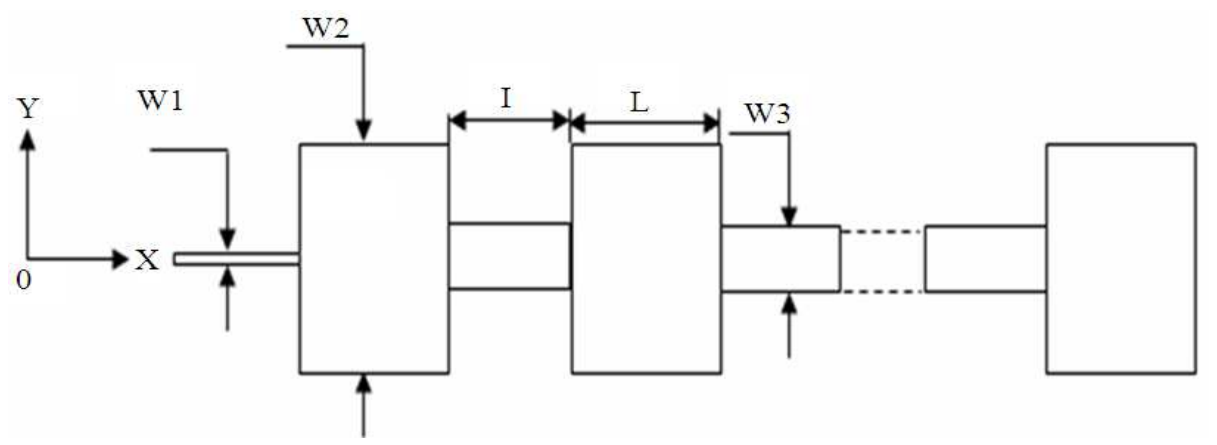

Fig. 1. Linear array antenna with $n$ elements

Initially, we begin by determining the bond graph model of this array with four elements. To make this bond graph model rigorous, we will consider the adaptation between radiating elements using quarter-wave transformers.

\subsection{Determining Model Band Graph of the}

\section{Antenna}

\subsubsection{Model Band Graph of Narrow Microstrip Lines}

There are two interests of inserting these quarter wavelength transformers between the radiating element and the feed line. The first interest is to achieve a successive impedance transformation which is necessary for adapting it to all the points in the network. The second is to perform the adaptation of the antenna $50 \Omega$ at the excitation points Houssini (2009). Figure 2 shown a narrow microstrip lines and its equivalent electric element. Figure 3 present a bond graph model of a narrow microstrip lines.

With $\mathrm{I}$ is the inductive element.

\subsection{Model Band Graph of Rectangular Patch}

Also the rectangular patch can translate by the bond graph model shown by Fig. 4 Mehouachi et al. (2012b).

In order to determine the value of $\mathrm{L}$ and the parameters of the patch, we use the following Equation 1 to 11 Mehouachi et al. (2012a):

$$
\begin{aligned}
& \mathrm{L}=\frac{\mathrm{Z}_{0 \mathrm{~L}} \cdot \mathrm{l}_{\mathrm{L}}}{v_{\mathrm{p}}} \\
& v_{\mathrm{p}}=\frac{\omega}{\beta} \\
& \beta=\frac{2 \pi}{\lambda_{\mathrm{g}}}
\end{aligned}
$$

$$
\begin{aligned}
& \lambda_{\mathrm{g}}=\frac{\lambda_{\mathrm{g}}}{\sqrt{\varepsilon_{\text {reff }}}} \\
& \varepsilon_{\text {reff }}=\frac{\varepsilon_{\mathrm{r}}+1}{2}+\frac{\varepsilon_{\mathrm{r}}-1}{2}\left(1+\frac{10 \mathrm{H}}{\mathrm{W}}\right)^{-1} \\
& \mathrm{Z}_{\mathrm{c}}=\frac{60 \pi}{\sqrt{\varepsilon_{\text {reff }}}}\left\{\begin{array}{l}
\frac{\mathrm{W}}{2 \mathrm{H}}+0.441+0.082\left(\frac{\varepsilon_{\text {reff }}-1}{\varepsilon_{\text {reff }}^{2}}\right)+ \\
\frac{\varepsilon_{\text {reff }}+1}{2 \pi \pi_{\text {reff }}}\left[1.451+\ln \left(\frac{\mathrm{W}}{2 \mathrm{H}}+0.94\right)\right]
\end{array}\right\}^{-1} \\
& \mathrm{C}_{\mathrm{p}}=\frac{\varepsilon_{\text {reff }} \varepsilon_{0} \mathrm{LW}+1}{2 \mathrm{H}}+\operatorname{COS}^{-2}\left(\frac{\pi \mathrm{x}_{0}}{\mathrm{~L}}\right) \\
& \mathrm{R}_{\mathrm{p}}=\frac{\mathrm{Q}_{\mathrm{T}}}{\mathrm{w}_{\mathrm{r}} \mathrm{C}_{\mathrm{P}}}
\end{aligned}
$$

$\mathrm{Q}_{\mathrm{T}}$ : Quality factor:

$$
\mathrm{w}_{\mathrm{p}}=2 \pi \mathrm{f}_{\mathrm{r}}
$$

$\mathrm{L}_{\mathrm{p}}=\frac{1}{\mathrm{Cw}_{\mathrm{r}}^{2}}$

$$
\mathrm{L}_{1}=\frac{377}{\sqrt{\varepsilon_{\text {reff }}}} \tan \left(\frac{2 \pi \pi}{\lambda_{0}}\right)
$$

$\mathrm{x}_{0}$ is the position of the probe on the patch according to the $\mathrm{x}$ axis.

After taking into account the adaptation of feeding to the radiating element, the previous models help us to determine the general model of linear antenna array consists of four elements fed in series. Figure 5 shows the band graph model of this antenna. 


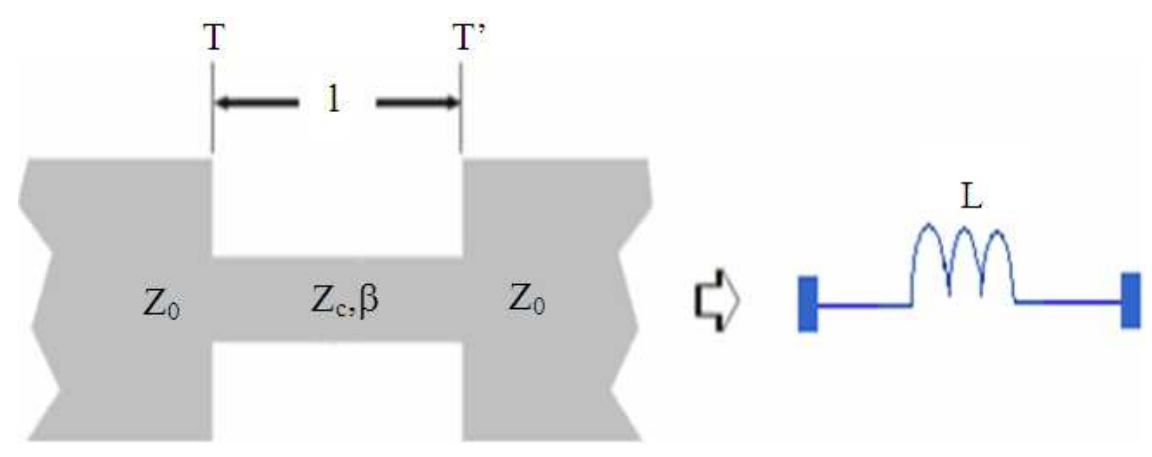

Fig. 2. Narrow microstrip lines and its equivalent electric elemente

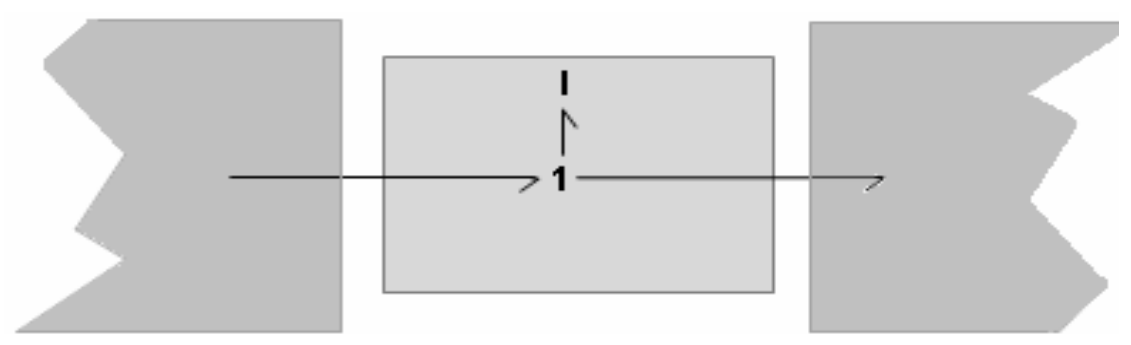

Fig. 3. Bond graph model of narrow microstrip lines

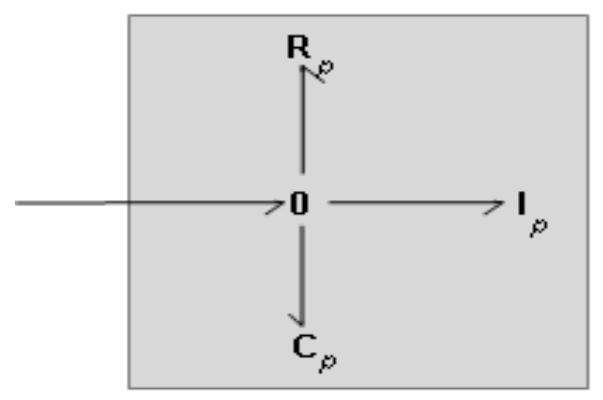

Fig. 4. Bond graph model of rectangular patch

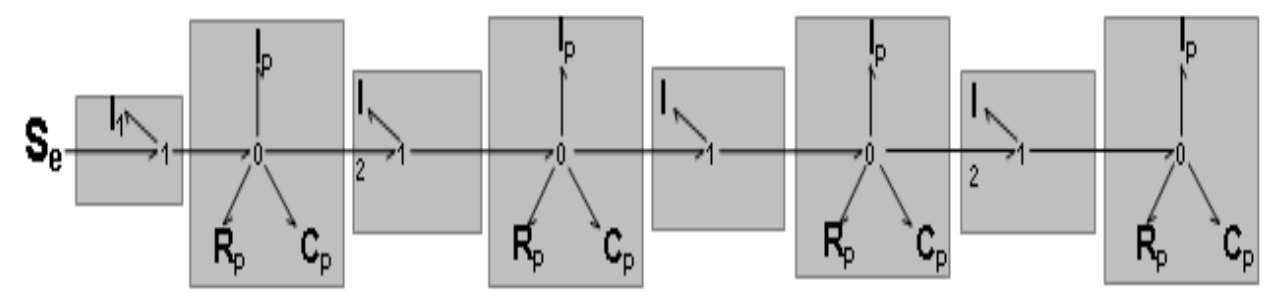

Fig. 5. Band graph model of antenna array consists of four elements

\subsection{Scattering Band Graph Model of Antenna}

The bond graph is widely used for modeling the physical system which operates in low frequency. This technique is based on the exchange of energy to model and simplify complex systems. Mr Hichem Taghouti and $\mathrm{Mr}$ Abdelkader Mami have developped this approach in Taghouti and Mami $(2009 ; 2010)$ so that 
the bond graph becomes capable to model the highest frequency systems. The bond graph model of our antenna array is shown in Fig. 6.

We can make a decomposition of the bond graph shown above Mehouachi et al. (2012a) and the new model is shown in Fig. 7.

The reduced and causal bond graph model can be decomposed in four sub-models Taghouti and Mami (2010; 2011) as shown in Fig. 8.

Each sub-model can be simplified by the reduced bond graph model with effort-flow causality Taghouti and Mami (2009). All this is summarized in Fig. 9.

For this type of reduced and causal bond graph, we will have the following matrix Mehouachi et al. (2012a); Taghouti and Mami (2012) Equation 12:

$$
\left[\begin{array}{l}
\varphi_{1} \\
\varepsilon_{2}
\end{array}\right]=\left[\begin{array}{ll}
\mathrm{H}_{11} & \mathrm{H}_{12} \\
\mathrm{H}_{21} & \mathrm{H}_{22}
\end{array}\right]\left[\begin{array}{l}
\varepsilon_{1} \\
\varphi_{2}
\end{array}\right]
$$

The matrix $\mathrm{H}$ is presented by the following Equation 13 to 17 :

$$
\mathrm{H}=\left[\begin{array}{ll}
\mathrm{H}_{11} & \mathrm{H}_{12} \\
\mathrm{H}_{21} & \mathrm{H}_{22}
\end{array}\right]
$$

$$
\begin{aligned}
& \mathrm{z}_{\mathrm{i}}=\tau_{\mathrm{Li}} \mathrm{s} \\
& \mathrm{y}_{\mathrm{p}}=\tau_{\mathrm{Cp}} \mathrm{s}+\frac{1}{\tau_{\mathrm{Lp}} \mathrm{s}}+\frac{1}{\tau_{\mathrm{Rp}}}
\end{aligned}
$$

Where:

$$
\begin{aligned}
\tau_{\mathrm{Li}} & =\frac{\mathrm{L}_{\mathrm{i}}}{\mathrm{R}_{0}} \\
\tau_{\mathrm{Ci}} & =\mathrm{R}_{0} * \mathrm{C}_{\mathrm{i}} \\
\mathrm{R}_{0} & =\text { The scaling resistance and } \\
\mathrm{S} & =\text { The Laplace operator }
\end{aligned}
$$

Hij represent the integro-differentiels operators associated to the causal ways connecting the port $\mathrm{P}_{\mathrm{j}}$ to the port $\mathrm{P}_{\mathrm{i}}$ and obtained by the general form given below Equation 18 and 19:

$$
\begin{aligned}
& \mathrm{H}_{\mathrm{ij}}=\sum_{\mathrm{k}=1}^{\mathrm{n}} \frac{\mathrm{T}_{\mathrm{k}} \Delta_{\mathrm{k}}}{\Delta} \\
& \Delta=1-\sum \mathrm{B}_{\mathrm{i}}+\sum \mathrm{B}_{\mathrm{i}} \mathrm{B}_{\mathrm{j}}-\sum \mathrm{B}_{\mathrm{i}} \mathrm{B}_{\mathrm{j}} \mathrm{B}_{\mathrm{k}}+\ldots
\end{aligned}
$$

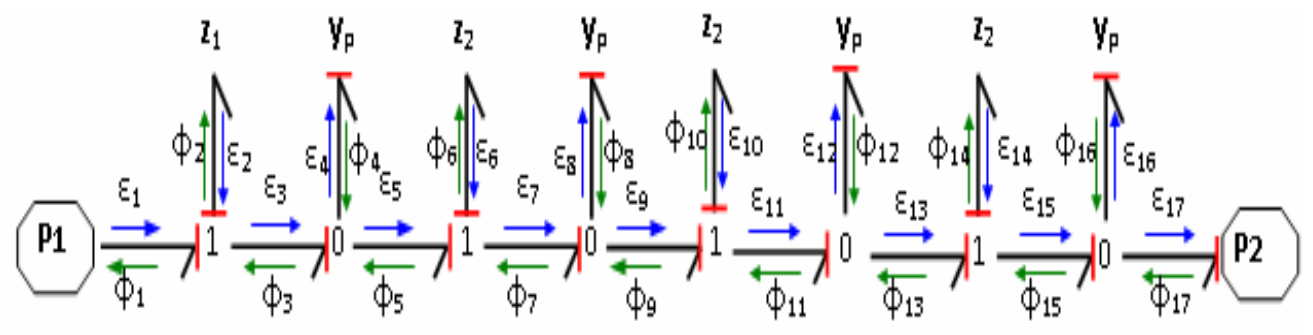

Fig. 6. Reduced and causal bond graph model of antenna array with four elements

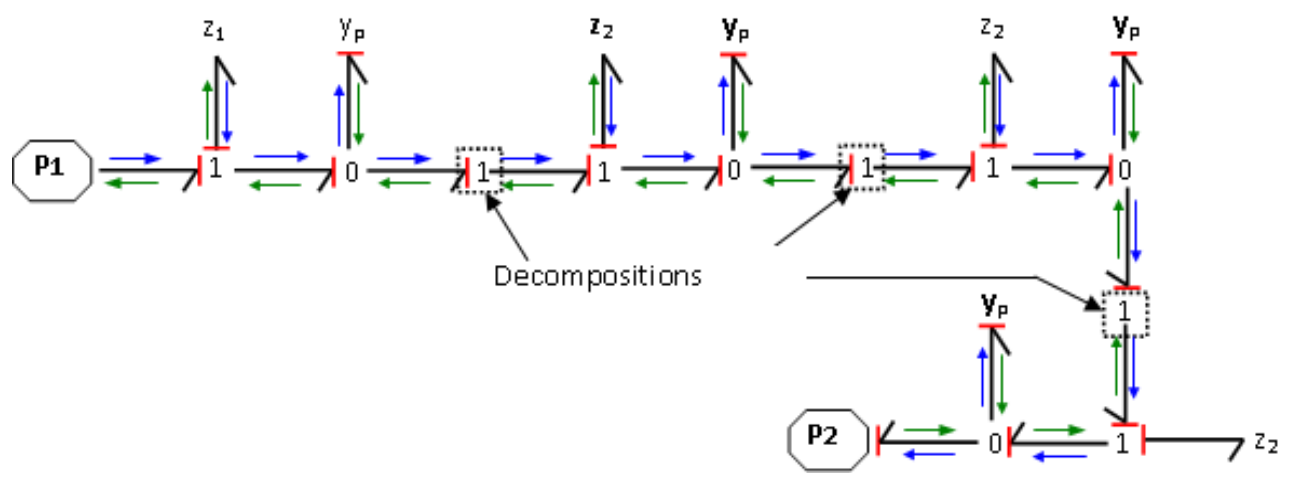

Fig. 7. Decomposition of reduced and causal bond graph model of antenna array 

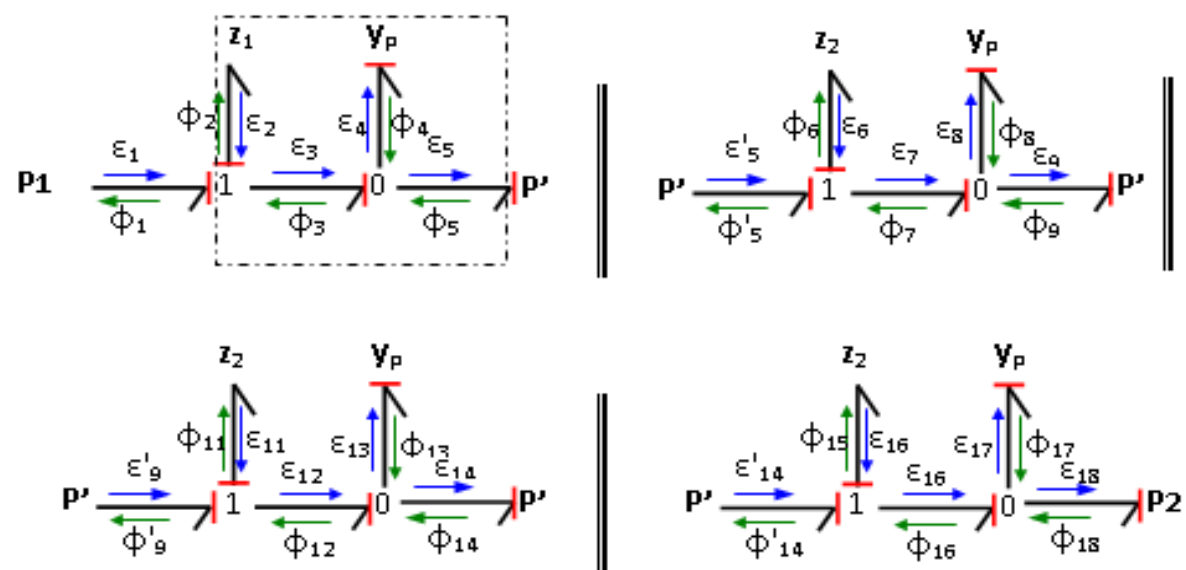

Fig. 8. The four sub-models

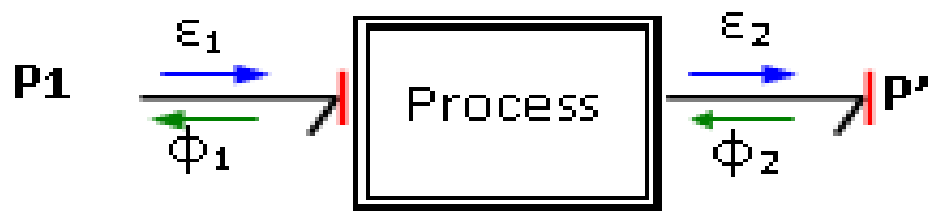

Fig. 9. Reduced bond graph model with effort- flow causality

\footnotetext{
$\Delta \quad=$ The determinant of the causal bond graph

$\mathrm{H}_{\mathrm{ij}} \quad=$ Complete gain between $\mathrm{P}_{\mathrm{j}}$ and $\mathrm{P}_{\mathrm{i}}$

$\mathrm{P}_{\mathrm{i}} \quad=$ Input port.

$\mathrm{P}_{\mathrm{j}} \quad=$ Output port.

$\mathrm{N}=$ Total number of forward path between Pi and $\mathrm{Pj}$

$\mathrm{T}_{\mathrm{k}}=$ Gain of the $\mathrm{k}^{\text {th }}$ forward path between Pi and $\mathrm{P}_{\mathrm{j}}$

$\mathrm{B}_{\mathrm{i}}=$ Loop gain of each causal algebraic loop in the bond graph model.

$\mathrm{B}_{\mathrm{i}} \mathrm{B}_{\mathrm{j}}=$ Product of loop gains of any tow nontouching loops (no common causal bond).

$\mathrm{B}_{\mathrm{i}} \mathrm{B}_{\mathrm{j}} \mathrm{B}_{\mathrm{k}}=$ Product of the loop gains of any three pair wise no touching loops.

$\Delta_{\mathrm{k}}=$ The factor value of $\Delta$ for the $\mathrm{k}^{\text {th }}$ forward path, this value calculates himself as $\Delta$ when one only keeps the causal loops without touching the $\mathrm{k}^{\text {th }}$ chain of action
}

$\mathrm{L}_{\mathrm{i}}=\frac{-1}{\mathrm{z}_{\mathrm{i}} \mathrm{y}_{\mathrm{i}}}:$ Loop gain of algebraic given by each submodel shown in Fig. 6.
$\Delta_{\mathrm{i}}=1+\frac{1}{\mathrm{z}_{\mathrm{i}} \mathrm{y}_{\mathrm{i}}}$ : Determinant of causal bond graph of the model.

The following equations represent the integrodifferenciels operators of the model Equation 20:

$\left\{\begin{array}{l}\mathrm{H}_{11}=\frac{\mathrm{z}_{\mathrm{i}}}{\mathrm{z}_{\mathrm{i}} \mathrm{y}_{\mathrm{p}}+1} \\ \mathrm{H}_{12}=\frac{1}{\mathrm{z}_{\mathrm{i}} \mathrm{y}_{\mathrm{p}}+1} \\ \mathrm{H}_{21}=\frac{1}{\mathrm{z}_{\mathrm{i}} \mathrm{y}_{\mathrm{p}}+1} \\ \mathrm{H}_{22}=\frac{-\mathrm{y}_{\mathrm{p}}}{\mathrm{z}_{\mathrm{i}} \mathrm{y}_{\mathrm{p}}+1} \\ \Delta \mathrm{H}=\frac{-1}{\mathrm{z}_{\mathrm{i}} \mathrm{y}_{\mathrm{p}}+1}\end{array}\right.$

We can find for the effort- flow causality the wave matrix shown by the following Equation 21:

$$
\mathrm{W}=\frac{1}{2 \mathrm{H}_{21}}\left[\begin{array}{ll}
1-\mathrm{H}_{11}+\mathrm{H}_{22}-\Delta \mathrm{H} & 1-\mathrm{H}_{11}-\mathrm{H}_{22}+\Delta \mathrm{H} \\
1+\mathrm{H}_{11}+\mathrm{H}_{22}+\Delta \mathrm{H} & 1+\mathrm{H}_{11}-\mathrm{H}_{22}-\Delta \mathrm{H}
\end{array}\right]
$$




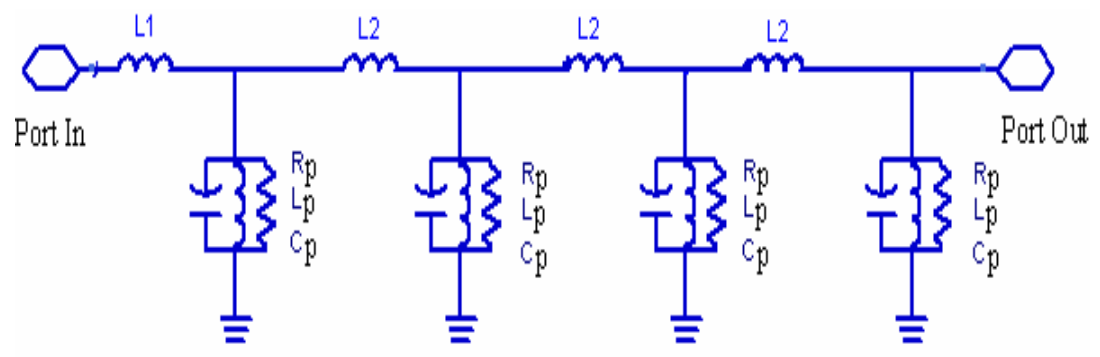

Fig. 10. Equivalent circuit of antenna array consists of four elements

From these operators, we can determine directly the wave matrix of each sub model i Equation 22:

$$
\mathrm{W}_{\mathrm{i}}=\frac{1}{2}\left[\begin{array}{cc}
\mathrm{z}_{\mathrm{i}} \mathrm{y}_{\mathrm{p}}+\mathrm{z}_{\mathrm{i}}+\mathrm{y}_{\mathrm{p}}+2 & \mathrm{z}_{\mathrm{i}} \mathrm{y}_{\mathrm{p}}-\mathrm{z}_{\mathrm{i}}+\mathrm{y}_{\mathrm{p}} \\
\mathrm{z}_{\mathrm{i}} \mathrm{y}_{\mathrm{p}}+\mathrm{z}_{\mathrm{i}}-\mathrm{y}_{\mathrm{p}} & \mathrm{z}_{\mathrm{i}} \mathrm{y}_{\mathrm{p}}-\mathrm{z}_{\mathrm{i}}-\mathrm{y}_{\mathrm{p}}+2
\end{array}\right]
$$

We can now deduce the wave matrix of the total model in this manner:

$$
\mathrm{W}_{\mathrm{T}}=\prod_{\mathrm{i}=1}^{4} \mathrm{~W}_{\mathrm{i}}=\left[\begin{array}{ll}
\mathrm{W}_{11} & \mathrm{~W}_{12} \\
\mathrm{~W}_{21} & \mathrm{~W}_{22}
\end{array}\right]
$$

From this total wave matrix, we can deduce the following scattering bond graph matrix Equation 24:

$$
\mathrm{S}_{\mathrm{T}}=\left[\begin{array}{cc}
\mathrm{W}_{12} \mathrm{~W}_{22}^{-1} & {\left[\mathrm{~W}_{11} \mathrm{~W}_{22}-\mathrm{W}_{21} \mathrm{~W}_{12}\right] \mathrm{W}_{22}^{-1}} \\
\mathrm{~W}_{22}^{-1} & -\mathrm{W}_{21} \mathrm{~W}_{22}^{-1}
\end{array}\right]
$$

If our antenna is composed of $\mathrm{n}$ patch so we extended the Equation 23 then we obtain the following formula Equation 25:

$$
\mathrm{W}_{\mathrm{Tn}}=\prod_{\mathrm{i}=1}^{\mathrm{n}} \mathrm{W}_{\mathrm{i}}
$$

The equivalent model electrical of a serial array antennas consists is inspired from the electrical model of patch antenna described by Ferchichi et al. (2009). This model is represented by Fig. 10. The values of resistors, capacitors and inductors are given by the same equation used in the bond graph method.

\section{RESULTS}

The use of this new bond graph technology allows us to get the following results, which are given by the
Fig. 11-18 which show reflection and transmissions coefficients of the antenna array after development a program in maple.

If we use the conventional method, we find the following results. Figures 19-26 show reflections and transmissions coefficients of the antenna array simulated under HP-ADS.

Through the previous results, we notice that the traditional method (simulations under HP-ADS) and the method of scattering bond graph have almost the same bandwidth and the same desired resonant frequency $\mathrm{f}_{\mathrm{r}}=$ $2.45 \mathrm{GHz}$. According to Fig. 11-18, we also find the coefficients of transmission and coefficient of reflection its almost identical to those simulated by the conventional method shown by Fig. 18-26.

Other hand, the physical interpretation of the above results shows that the antenna's gain is proportional to the number of patches: Using a single patch the gain is about $8.5 \mathrm{~dB}$ but if we use four patches, antenna's gain become at the order of $-17.5 \mathrm{~dB}$ as shown in Fig. 17. So, we can choose the number of elements in our antenna array according to the gain we want.

\section{DUSCUSSION}

This new bond graph technology, which was started in research works of Taghouti and Mami (2010); Khamailia et al. (2013) by simple electronic circuits will be extended by applying the formula given in Equation 25 for the modeling and simulation even antennas that contains à high number of patches, contrary to the work carried out by Ambresh et al. (2010), Ferchichi et al. (2009) and others who have limited the simulation of patches antennas to HFSS or HP-ADS softwares.

We note also that the simulation time is very different between the two methods. The simulation time by using the ADS softwares is about more than 60 seconds especially if we choose a high resolution but the bond graph method takes 5 seconds. 
Riadh Mehouachi et al. / American Journal of Applied Sciences 11 (8): 1436-1449, 2014

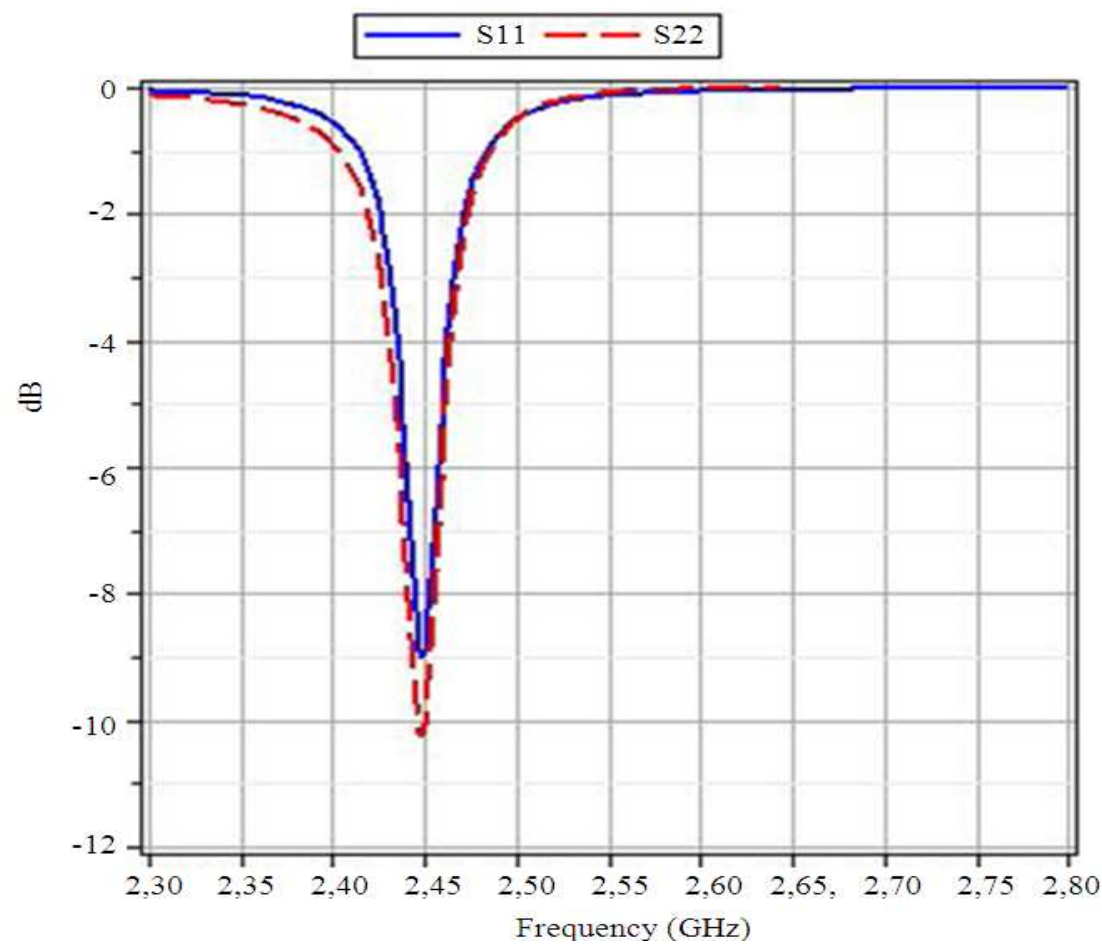

Fig. 11. Simulations of reflections coefficients using a single patch

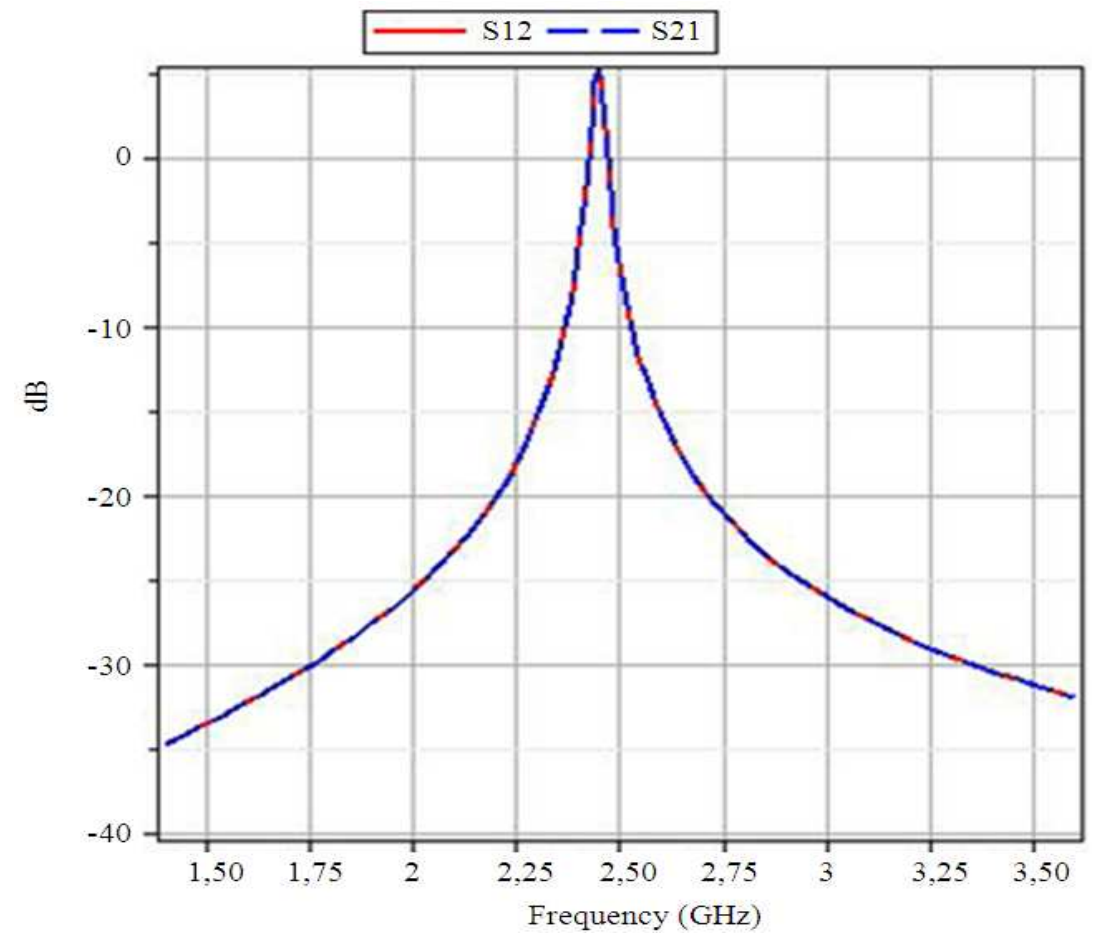

Fig. 12. Simulations of transmissions coefficients using a single patch 
Riadh Mehouachi et al. / American Journal of Applied Sciences 11 (8): 1436-1449, 2014

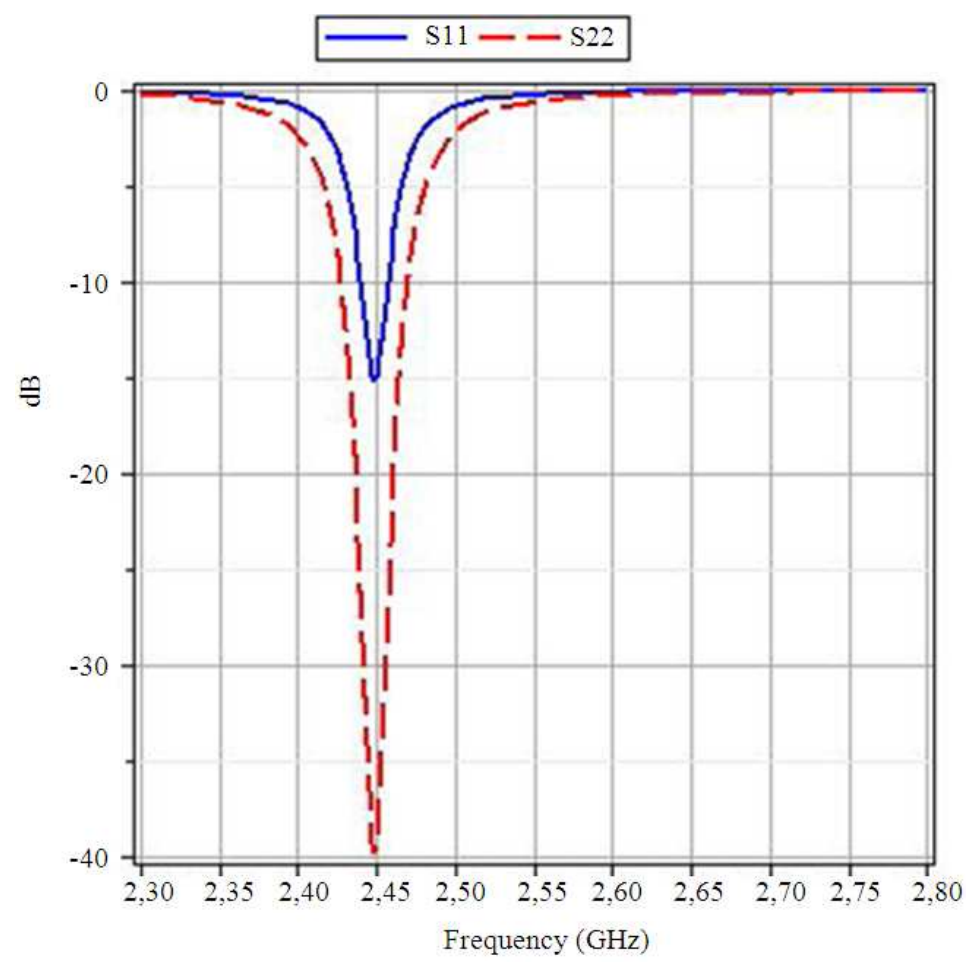

Fig. 13. Simulations of reflections coefficients using an antenna array consisting of two patches

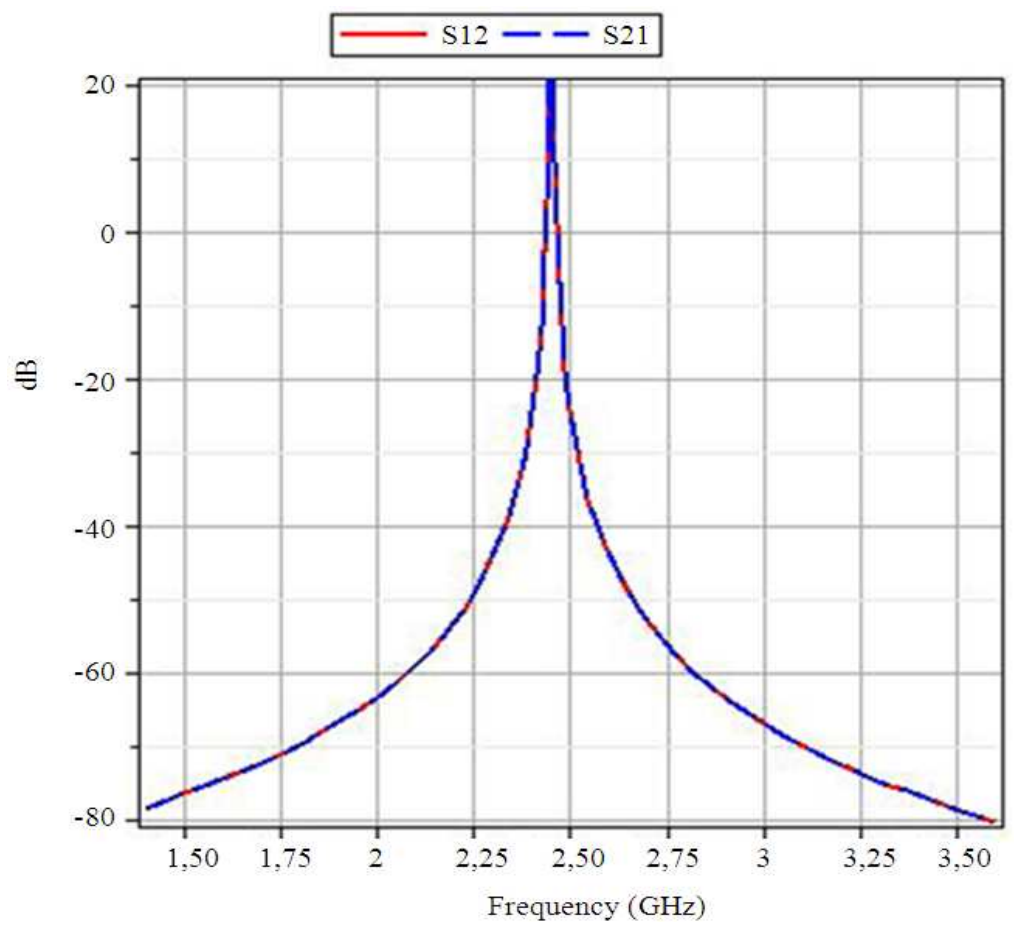

Fig. 14. Simulations of transmissions coefficients using an antenna array consisting of two patches 
Riadh Mehouachi et al. / American Journal of Applied Sciences 11 (8): 1436-1449, 2014

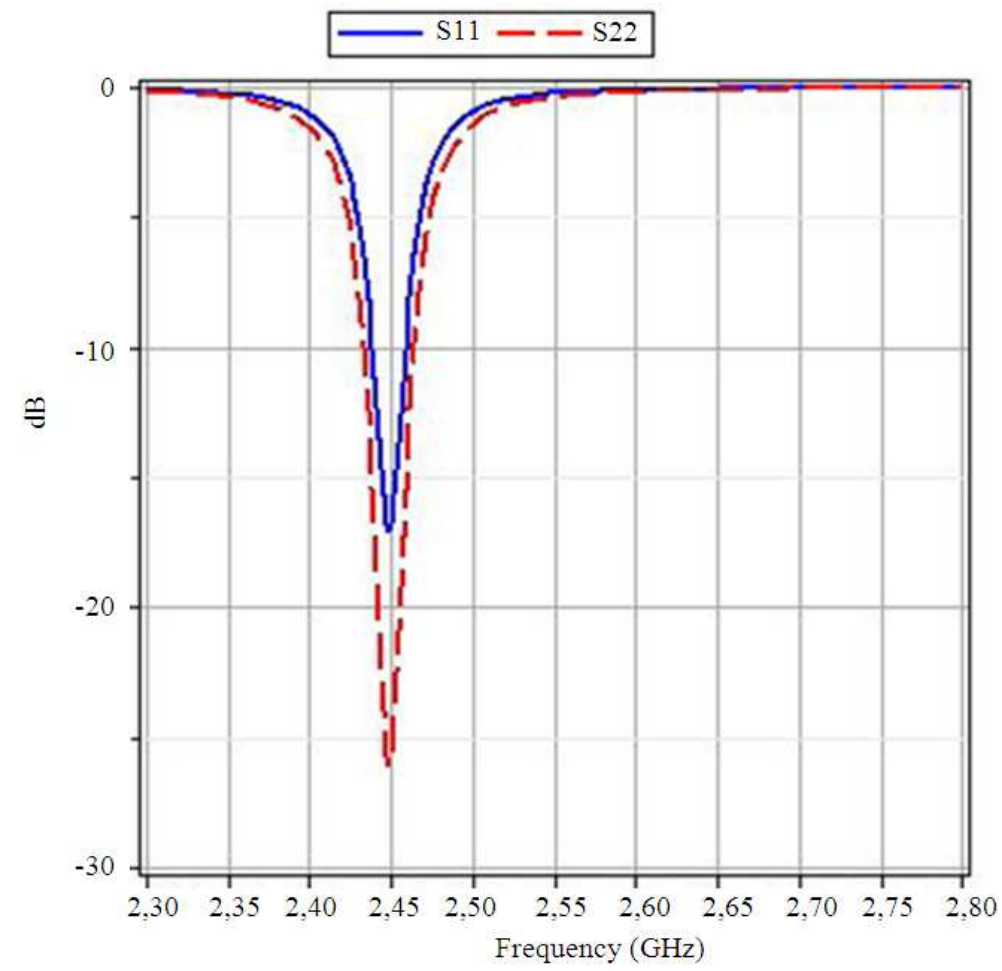

Fig. 15. Simulations of reflection coefficients using an antenna array consisting of three patches

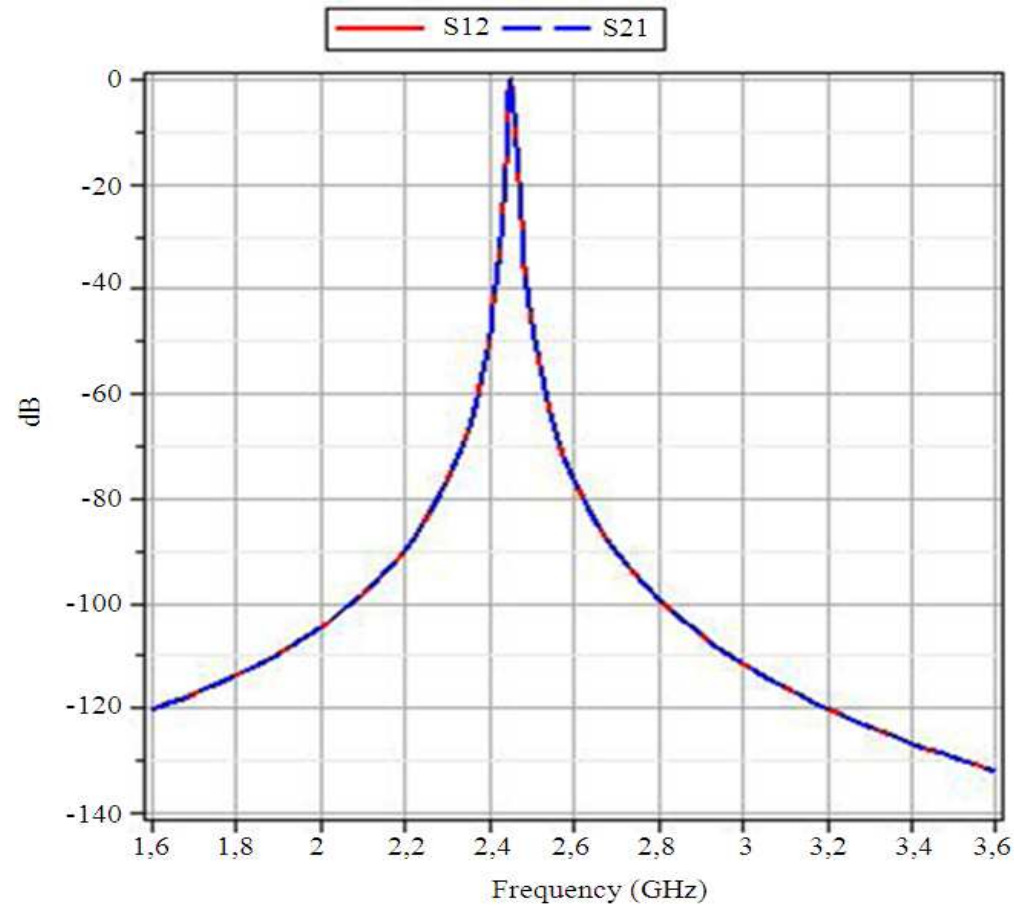

Fig. 16. Simulations of transmissions coefficients using an antenna array consisting of three patches 
Riadh Mehouachi et al. / American Journal of Applied Sciences 11 (8): 1436-1449, 2014

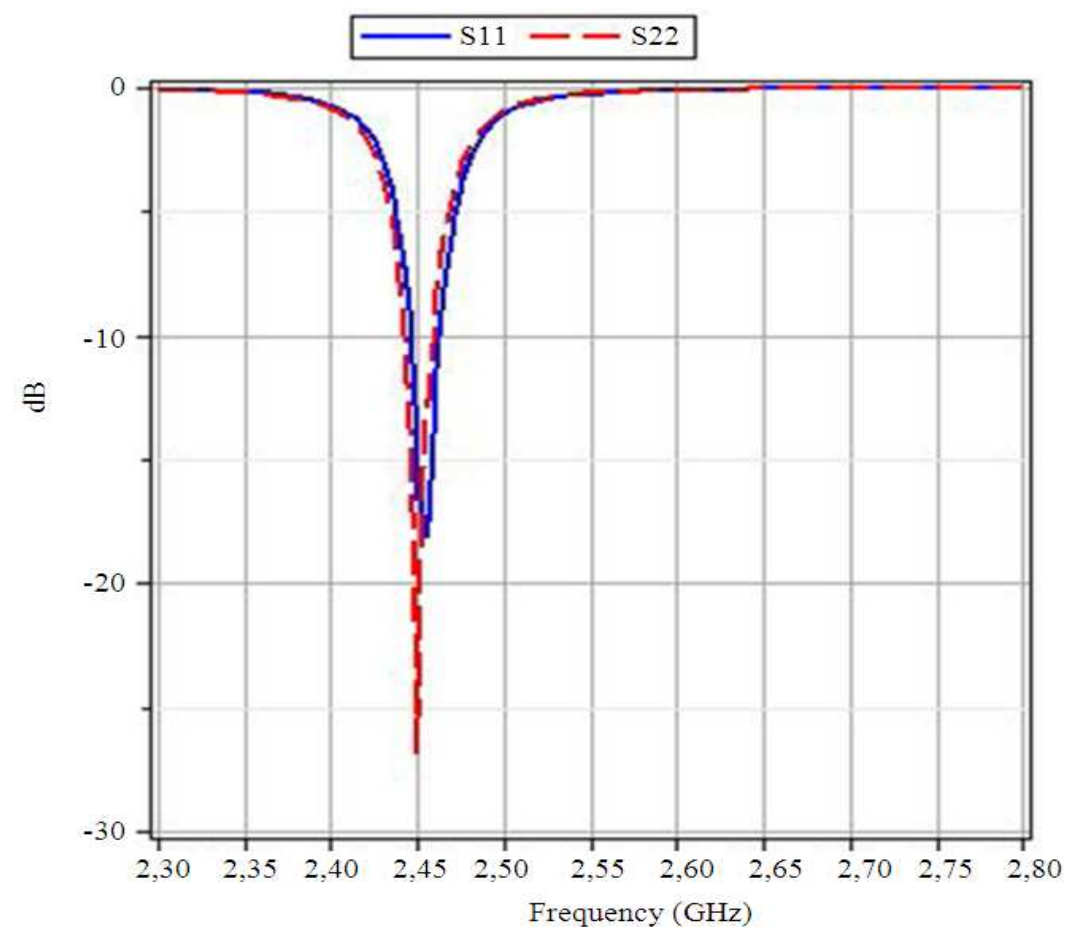

Fig. 17. Simulations of reflections coefficients using an antenna array consisting of four patches

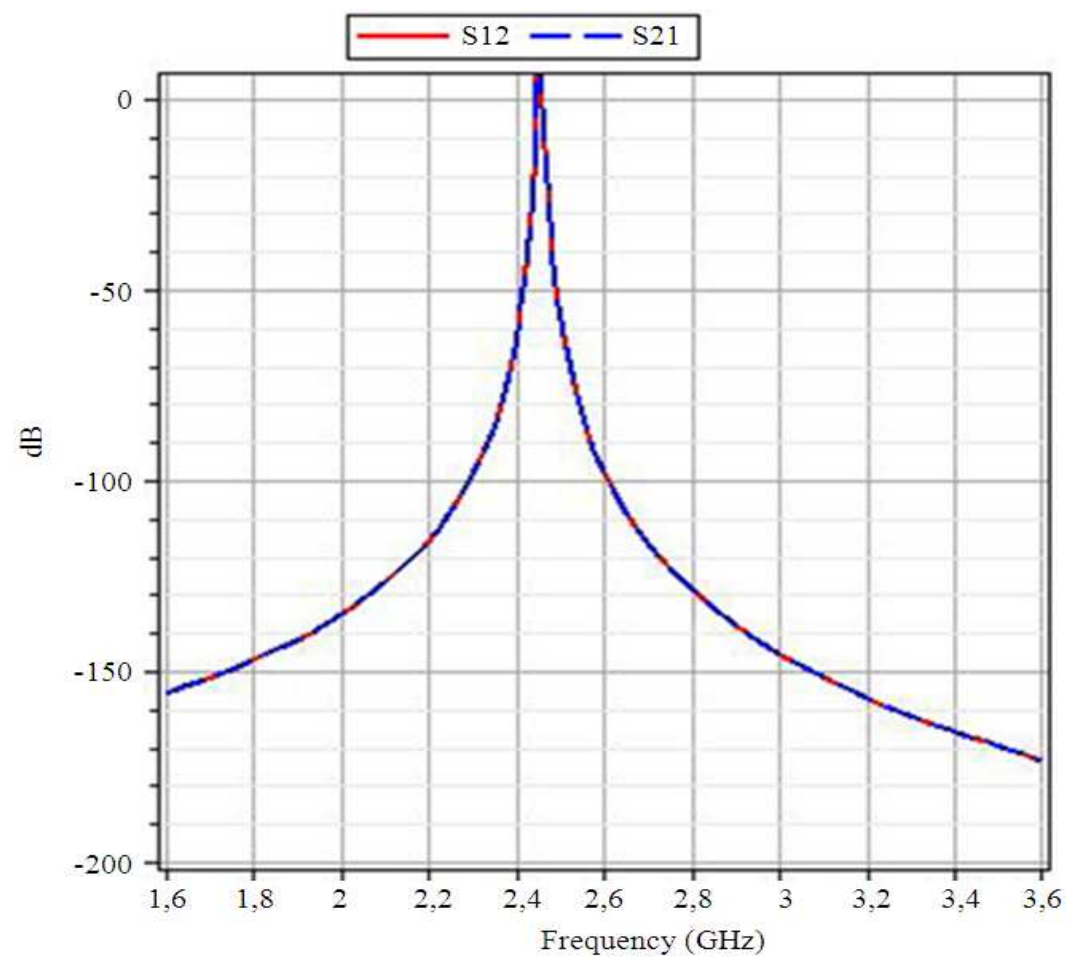

Fig. 18. Simulations of transmissions coefficients using an antenna array consisting of four patches 
Riadh Mehouachi et al. / American Journal of Applied Sciences 11 (8): 1436-1449, 2014

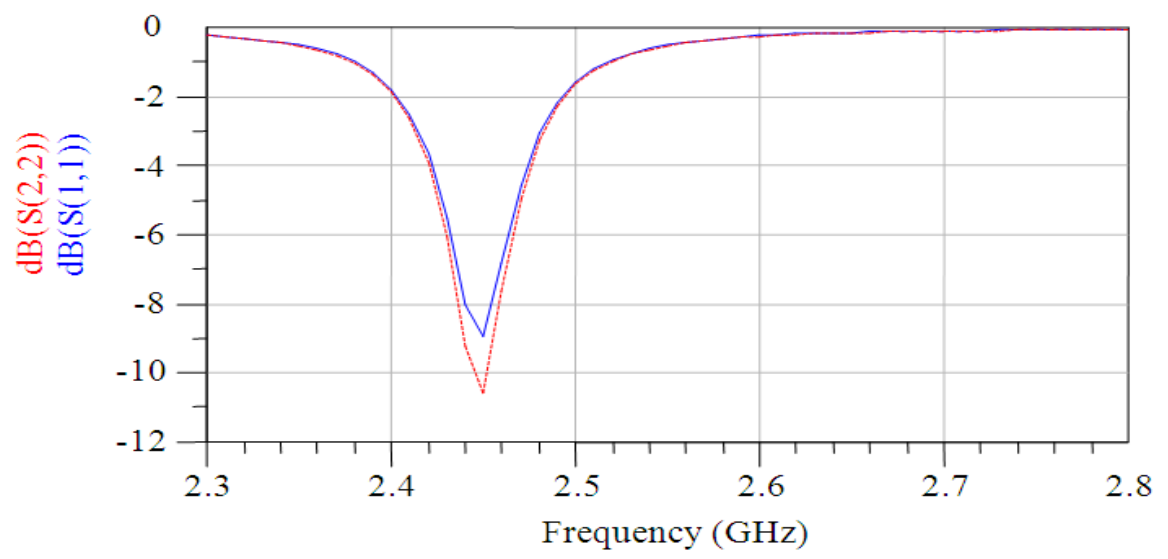

Fig. 19. Simulations of coefficients using a single patch under HP-ADS

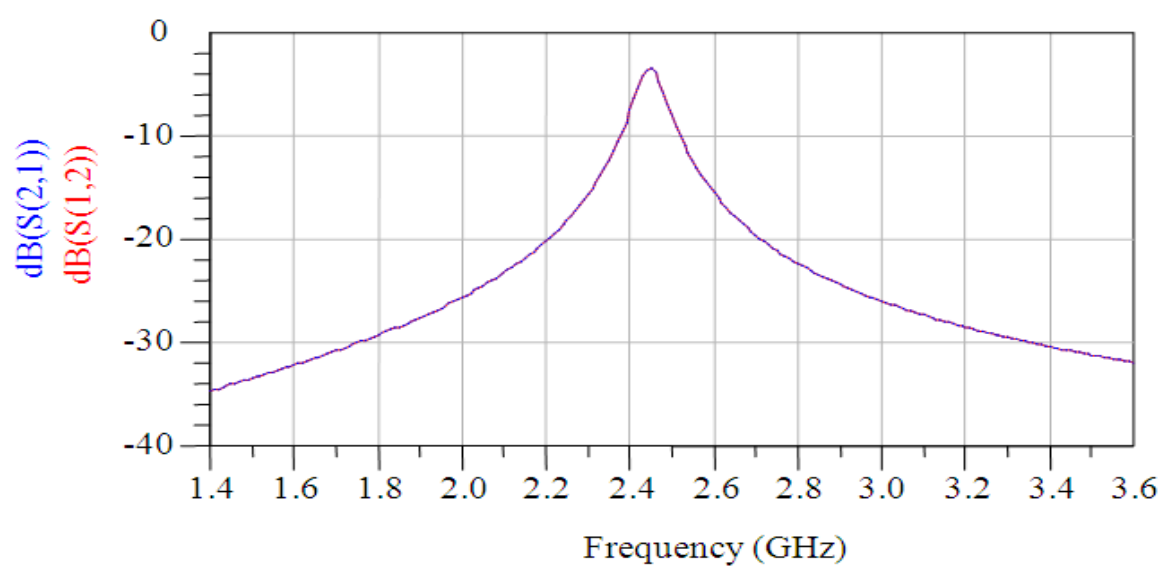

Fig. 20. Simulations of transmissions coefficients using a single patch under HP-ADS

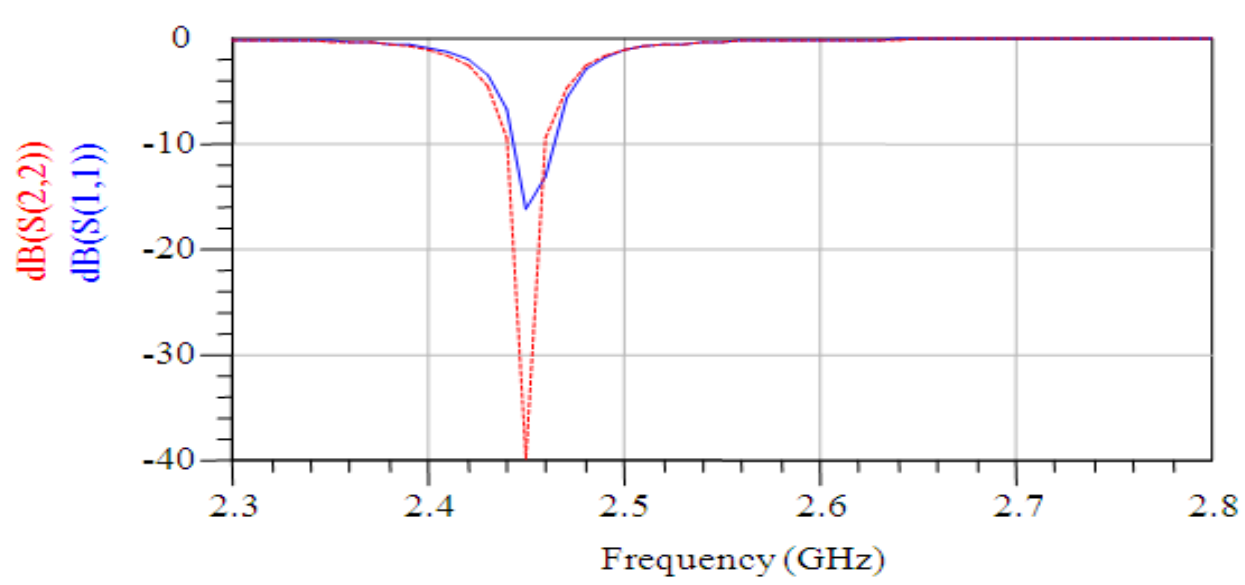

Fig. 21. Simulations of reflections coefficients using an antenna array consisting of two patches under HP-ADS 
Riadh Mehouachi et al. / American Journal of Applied Sciences 11 (8): 1436-1449, 2014

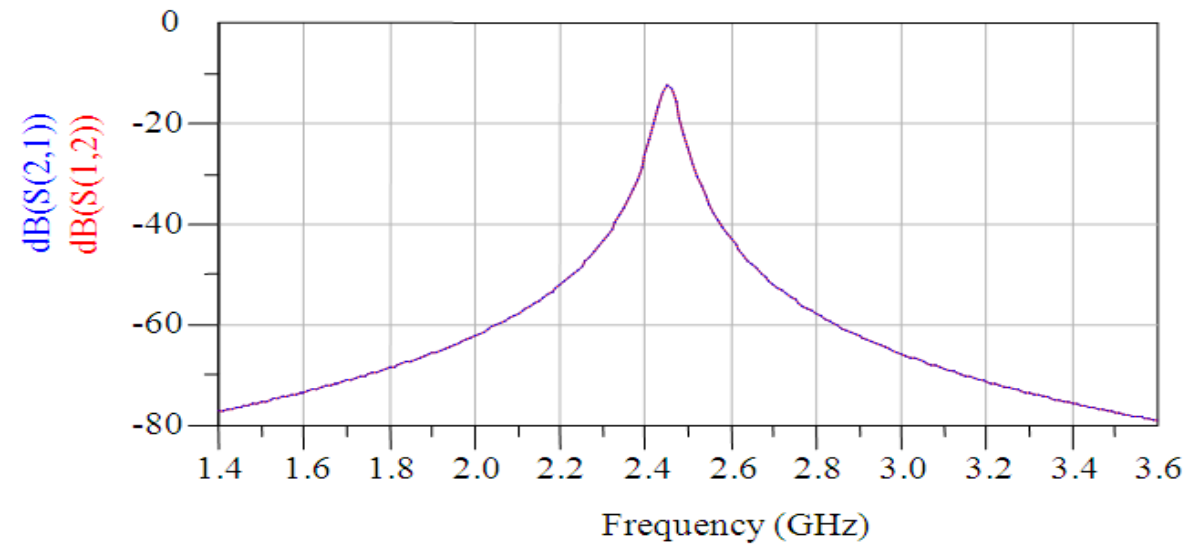

Fig. 22. Simulations of transmissions coefficients using an antenna array consisting of two patches under HP-ADS

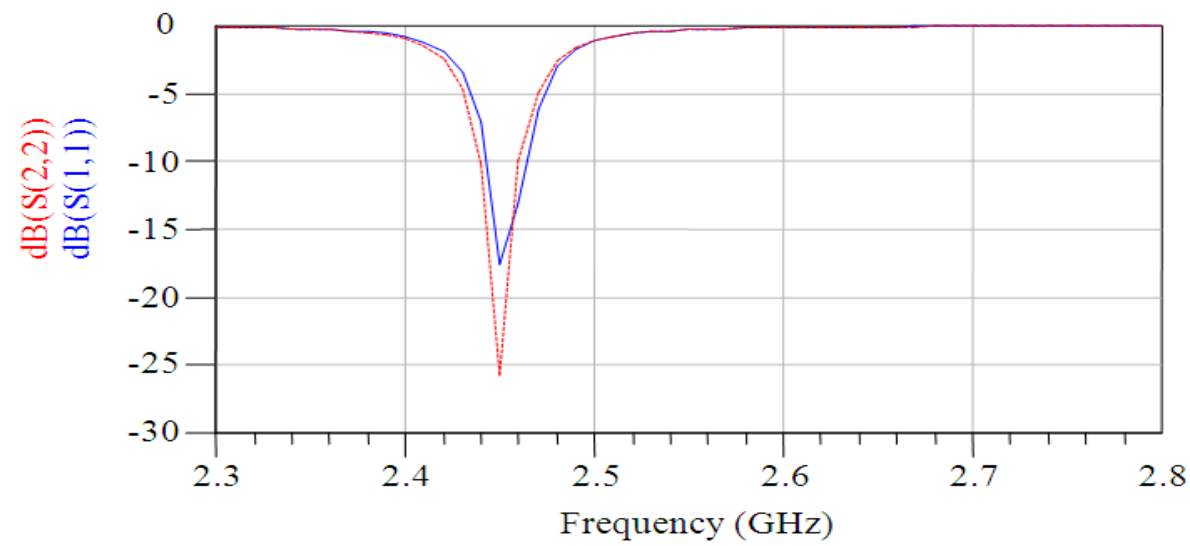

Fig. 23. Simulations of reflections coefficients using an antenna array consisting of three patches under HP-ADS

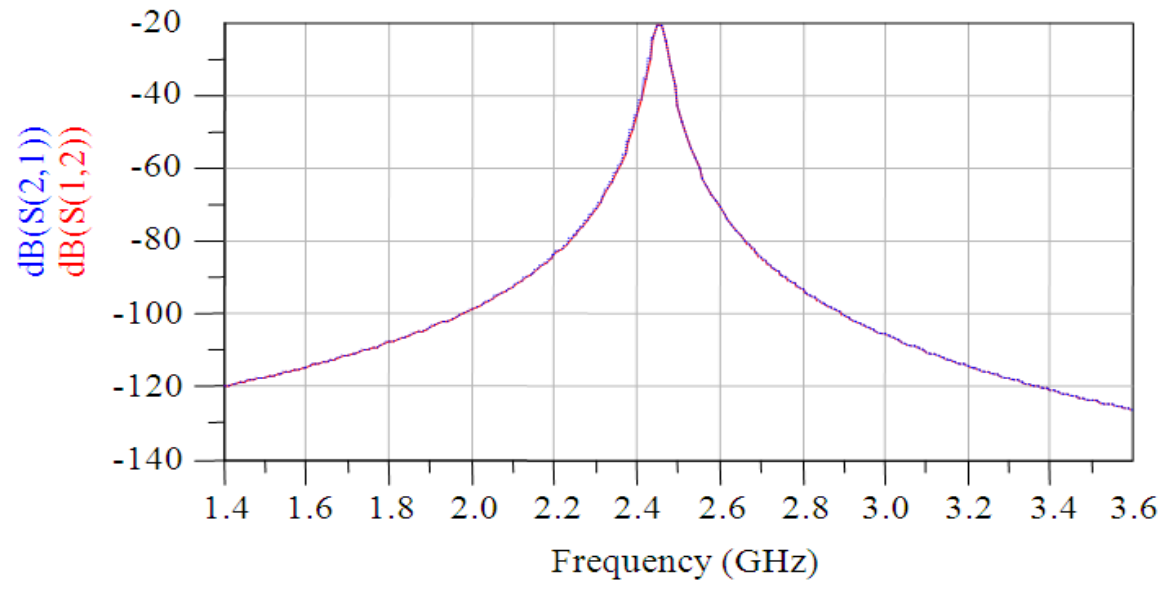

Fig. 24. Simulations of transmissions coefficients using an antenna array consisting of three patches under HP-ADS 


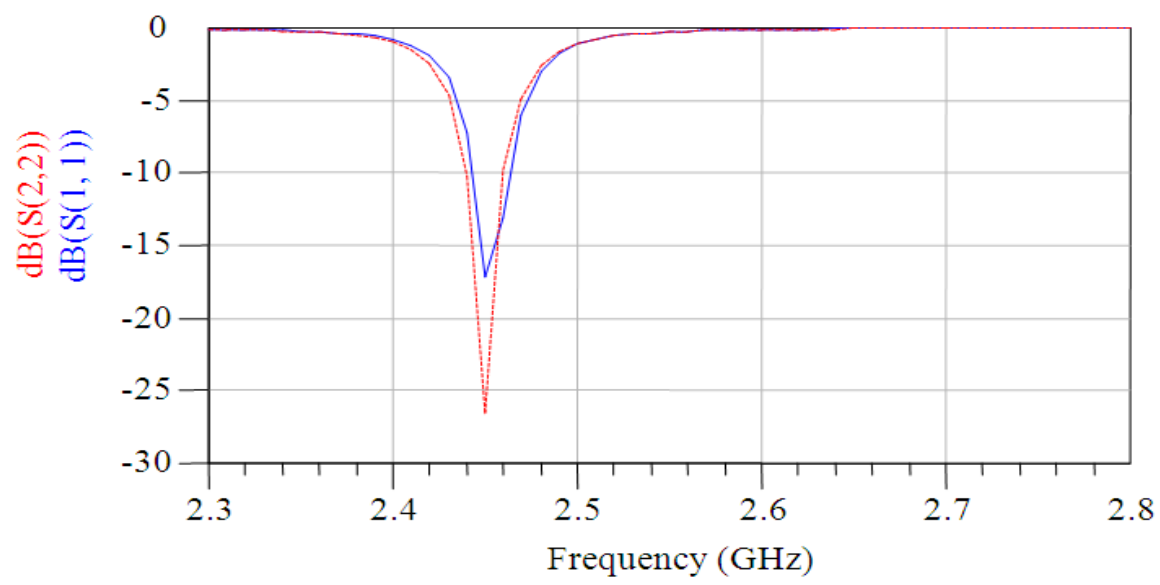

Fig. 25. Simulations of reflections coefficients using an antenna array consisting of four patches under HP-ADS

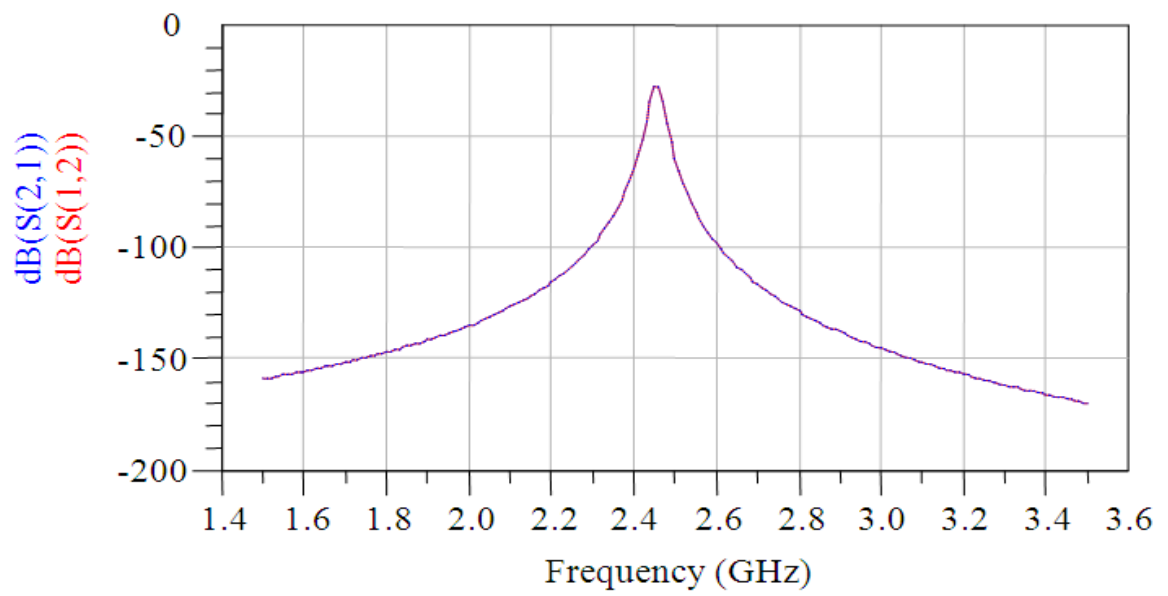

Fig. 26. Simulations of transmissions coefficients using an antenna array consisting of four patches under HP-ADS

\section{CONCLUSION}

An analysis of microstrip antenna in linear array using the method of scattering bond graph was presented and was presented and explained briefly. Results are almost the same results obtained with the conventional method but with greater precision. Furthermore, our method takes into account the exchange of power between the different elements of the antenna array. This new type of analysis enables us to get the best results in a more economical and easier way. For the simulation, we need a simple programming under Maple without the need of the HP-ADS software. The proposed method is very useful due to its simplicity, the reduced cost, reduced simulation time and the possibility to control antenna parameters. These benefits are very important in our field of study. In our future work, we will extend our method to simulate different forms of patches even those that are very complicated as array of bwe tie antenna and we will determine also their radiation pattern.

\section{ACKNOWLEDGMENT}

We would like to thank especially Prof. MAMI Abdelkader for the time and guidance given throughout the all carried out works, without forgetting the members of the unit of electronics and high frequency 
circuits and all those who contributed and aided for this study in particularly LACS members (Laboratory of analysis and command systems).

\section{REFERENCES}

Ambresh, P.A., P.M. Hadalgi and P.V. Hunagund, 2010. Study of slot inserted inverted patch-rectangular microstrip antenna for wireless applications. Int. J. Electron. Eng., 2: 295-298.

Ferchichi, A., N. sboui and A. Gharssallah, 2009. A modified bow tie antenna for RFID application. Proceedings of the International Conference Sciences of Electronic Technologies of Information and Telecommunications, Mar. 22-26, Tunisia.

Houssini, M, 2009. 26 "Conception de circuits reconfigurables à base de MEMS Thesis $\mathrm{N}^{\circ}: 9-2009$.

Khamailia, S., A. Mami and H. Taghouti, 2013. Modeling of a microstrip low- pass filter by the scattering- bond graph formalism. Int. J. Comput. Sci. Iss., 10: 158-164.

Mehouachi, R., H. Taghouti, S. Khmailia and A. Mami, 2012a. Modelling and determination of scattering parameters of wideband patch antenna by using a Band Graph approach. Int. J. Eng. Res. Applic., 2: 879-884.

Mehouachi, R., H. Taghouti1, S. Khmailia1 and A. Mami, 2012b. Modeling and simulation of the patch antenna by using a Bond Graph approach. Int. J. Adv. Eng. Technol., 2: 474-484.
Paynter, H.M., 1992. An Epistemic Prehistory of Bond Graphs. In: Interesting Historic Perspective by the Inventor Himself, Breedveld, P.C. and G. DauphinTanguy (Eds.). Bond Graphs for Engineers, Elsevier, Amsterdam, pp: 3-17.

Taghouti, H. and A. Mami, 2009. Application of the reduced bond graph approches to determinate the scattering parameters of high frequency filter. Proceedings of the 10th International Conference on Science and Techniques of Automatic Control and Computer Engineering, Dec. 20-22, Hammamet, Tunisia, pp: 379-391.

Taghouti, H. and A. Mami, 2010. Extraction, modelling and simulation of the scattering matrix of a chebychev low-pass filter with cut-off frequency $100 \mathrm{MHz}$ from its causal and decomposed bond graph model. ICGST-ACSE J.

Taghouti, H. and A. Mami, 2011. New extraction method of the scattering parameters of a physical system starting from its causal bond graph model: Application to a microwave filter. Int. J. Phy. Sci., 6: 3016-3030.

Taghouti, H. and A. Mami, 2012. Discussion around the scattering matrix realization of a microwave filter using the bond graph approach and scattering formalism. Am. J. App. Sci., 9: 459-467. DOI: 10.3844/ajassp.2012.459.467 